\title{
DINÂMICA DAS POPULAÇÕES BACTERIANAS EM SOLOS DE CERRADOS'
}

\author{
JOÃO CARLOS PEREIRA², MARIA CRISTINA PRATA NEVES ${ }^{3}$ e ADAM DROZDOWICZ ${ }^{4}$
}

\begin{abstract}
RESUMO - Nos ambientes tropicais, os Cerrados destacam-se pelo seu potencial agrícola. Apesar das funções dos microrganismos no crescimento das plantas e na produtividade das culturas, existem poucas informações dos efeitos resultantes do manejo do solo, na ecologia microbiana. Neste estudo, foram avaliados os efeitos das condições ambientais e das práticas agrícolas sobre as populações bacterianas. As densidades das populações em solos com vegetação nativa foram variáveis e diferenciadas. Em Sete Lagoas, MG, as populações de actinomicetos variaram de 1,7 a 50 X $10^{4} \mathrm{UFC} / \mathrm{g}$ de solo seco, enquanto em Planaltina as densidades das populações bacterianas em solo com primeiro e segundo ano de cultivo de soja foram semelhantes, mas superiores ao solo com vegetação nativa. A utilização agrícola deste solo não resultou em desequilíbrios acentuados das populações de actinomicetos provenientes de esporos e hifas. As relações esporos/hifas variaram de 1,1 a 5,8. Na rizosfera da soja, os coeficientes de correlação entre as populações de actinomicetos com as demais populações bacterianas foram significativos. Os resultados evidenciam que as práticas agrícolas utilizadas na introdução da cultura da soja em solos de Cerrados pode influenciar o equilíbrio das populações na comunidade bacteriana.
\end{abstract}

Termos para indexação: actinomicetos, soja, Glycine max.

\section{DYNAMIC OF BACTERIAL POPULATIONS FROM CERRADO SOILS}

\begin{abstract}
Among tropical environments, Cerrados stand out because of its agriculture potencial. Although microorganisms play an important role on soil sustainability and crop production, few information is available on the effects of soil management systems on Cerrado's microbial ecology. In this study the effects of environmental conditions and soil management practices on bacterial populations were evaluated. Bacterial population densities in soil under native vegetation were variable and diferentiated. Actinomycetes densities varied from 1.7 to $50 \mathrm{X} 10^{4} \mathrm{CFU} / \mathrm{g}$ dry soil in Sete Lagoas region, Brazil, whereas bacterial populations in both the first and second year of land use were similar and higher than those from soil under native vegetation in the Planaltina region. Soil management practices did not cause strong modifications in the equilibrium among actinomycetes populations obtained from both spores and hyphal. The spore/hypha ratios varied from 1.1 to 5.8. Correlation coefficients among actinomycetes and other bacteria populations were signifficant in soybeans rhizospheres. Results show that soil management practices used for soybean cultivation in Cerrado soils may influence the equilibrium of bacterial populations.
\end{abstract}

Index terms: actinomycetes, soybean, Glycine max.

${ }^{1}$ Aceito para publicação em 14 de setembro de 1998. Extraído da dissertação de Doutorado do primeiro autor.

${ }^{2}$ Eng. Agr., Ph.D., Embrapa-Centro Nacional de Pesquisa de Agrobiologia (CNPAB), Antiga Estrada Rio - São Paulo, Km 47, Caixa Postal 74505, CEP 23890-000 Seropédica, RJ. E-mail: jpereira@cnpab.embrapa.br

${ }^{3}$ Bióloga, Ph.D., Embrapa-CNPAB. E-mail: mcpneves@cnpab.embrapa.br

${ }^{4}$ Biólogo, Ph.D., Prof. Adjunto, Instituto de Microbiologia, Centro de Ciência da Saúde, UFRJ, Bloco I, Ilha do Fundão, CEP 21941-590 Rio de Janeiro, RJ.

\section{INTRODUÇÃO}

Os Cerrados apresentam-se como uma das alternativas com maior potencial para expansão agrícola brasileira. Por suas características de localização geográfica, clima e extensão, cerca de 112 milhões de hectares de terras aráveis são potencialmente aptas para o cultivo (Peres et al., 1992).

A comunidade microbiana nos solos é influenciada pelo ambiente. As modificações ambientais 
provocadas pela flutuação estacional das condições climáticas também podem influenciar as populações na comunidade microbiana (Wardle \& Parkinson, 1990). Nos ecossistemas naturais, a cobertura vegetal permanente proporciona proteção contínua do solo, além de adicionar grandes quantidades de nutrientes principalmente através de resíduos. Seus efeitos sobre a comunidade microbiana podem interagir com os efeitos provocados pelas flutuações hídricas e térmicas que ocorrem durante o ano, influenciando em menor ou maior grau as populações microbianas, através da determinação da atividade e das taxas de crescimento das diversas populações na comunidade microbiana (Tsai et al., 1992).

Nos agroecossistemas, o preparo e o cultivo do solo influenciam as populações da comunidade microbiana, principalmente através de alterações na aeração e na disponibilidade de nutrientes no solo. A calagem e a adubação são alternativas técnicas utilizadas para corrigir a elevada acidez e a baixa fertilidade dos solos de Cerrados. Entretanto, as alterações do $\mathrm{pH}$ e da disponibilidade de nutrientes podem influenciar a comunidade microbiana de maneira direta através da atuação sobre processos microbianos, fisiológicos e bioquímicos específicos, ou indiretamente através da disponibilidade de nutrientes e da neutralização de elementos tóxicos (Kamel et al., 1989).

O equilíbrio dinâmico das populações na comunidade microbiana dos solos também pode sofrer modificações influenciadas pelas interações benéficas e/ou antagônicas dos microrganismos, determinando a composição qualitativa e quantitativa da comunidade (Raverkar \& Konde, 1988).

O conhecimento do equilíbrio dinâmico e dos efeitos das práticas agrícolas sobre as populações na comunidade bacteriana é importante, dadas as inúmeras funções que esses microrganismos desempenham. Embora as pesquisas direcionadas para este tipo de informação sejam relativamente intensas em solos de regiões temperadas, ainda são incipientes em relação aos solos das regiões subtropicais e tropicais. Além disso, tem-se observado que o número de variáveis avaliadas é bastante limitado. Há poucos dados comparáveis entre as populações microbianas presentes em solos de ecossistemas naturais e em agroecossistemas, durante as estações climáticas em anos consecutivos, como também há poucos registros sobre a dinâmica da comunidade microbiana da rizosfera das plantas cultivadas.

Este trabalho teve como objetivo avaliar as influências das condições ambientais e das práticas agrícolas utilizadas no cultivo da soja, sobre a comunidade bacteriana em dois solos de Cerrados.

\section{MATERIAL E MÉTODOS}

A dinâmica das populações bacterianas em solos de Cerrados foi avaliada em amostras de solos obtidos no campo experimental da Embrapa-Centro Nacional de Pesquisa de Milho e Sorgo, em Sete Lagoas, MG (Latossolo Vermelho-Escuro), e da Embrapa-Centro de Pesquisa Agropecuária dos Cerrados, em Planaltina, DF (Latossolo Vermelho-Amarelo).

\section{Sete Lagoas, MG}

Foram utilizados os tratamentos: 1- Solo com vegetação nativa (Ecossistema natural); e 2- Solo com primeiro cultivo de soja (Glycine max (L.) Merrill) (Agroecossistema). Na cultivar Doko foi inoculada a mistura das estirpes BR 33 (CB 1809) de Bradyrhizobium elkanni e BR 40 (SEMIA 566) de Bradyrhizobium japonicum e semeada em linhas com densidade de 25 sementes por metro e com espaçamento de $0,5 \mathrm{~m}$ entre linhas. Estas áreas foram dispostas em faixas e formadas por parcelas de $15 \mathrm{~m}$ x $6 \mathrm{~m}$, com quatro repetições.

As amostras compostas por 20 subamostras foram coletadas em cada parcela, na profundidade de zero a $10 \mathrm{~cm}$, nos dias $3 / 11,6 / 3,1 / 4,7 / 5$ e $20 / 8$ de 1991 . O transporte das amostras foi feito por via aérea, para avaliações nos laboratórios da Embrapa-Centro Nacional de Pesquisa de Agrobiologia, em Seropédica, RJ, 48 horas após coleta no campo, definido preliminarmente como a melhor época para avaliar as densidades das populações na comunidade bacteriana, visto que a ação dos fatores ambientais abióticos são minimizadas (Pereira, 1995; Pereira et al., 1996). O solo de cada amostra também foi utilizado para determinação do teor de umidade, após secagem em estufa a $105^{\circ} \mathrm{C}$ até peso constante; outra fração foi destinada para a determinação do $\mathrm{pH}$ em água (Barreto et al., 1979).

Foram determinados o número de unidades formadoras de colônias (UFC) de bactérias/g solo seco e as freqüências médias de resistência natural apresentadas pelas populações bacterianas aos antibióticos nas concentrações utilizadas, assim como as freqüências médias das popula- 
ções de actinomicetos na comunidade bacteriana contabilizada.

As densidades das populações de bactérias em geral e de bactérias resistentes aos antibióticos foram avaliadas por meio de diluições seriadas das suspensões de solo com contagens das UFC em placas-de-petri contendo os meios de cultura descritos por Thornton (1922), sem antibióticos, e com 1,25 e $5,0 \mu \mathrm{g}$ de estreptomicina/mL e 2,5 e $10,0 \mu \mathrm{g}$ de cloranfenicol $/ \mathrm{mL}$, respectivamente. As UFC das populações de actinomicetos foram enumeradas no meio Waksman (1961). Tanto os meios como as concentrações dos antibióticos utilizados foram definidos previamente como os mais adequados para avaliar as densidades desses microrganismos em solos de Cerrados (Coelho, 1976; Pereira et al., 1996). Nesses meios, antes da esterilização, foi adicionada actidione (Cycloheximide, Sigma Chemical) suficiente para obter a concentração final de $300 \mu \mathrm{g} / \mathrm{mL}$ (Panthier et al., 1979).

As contagens das UFC das populações bacterianas em solos rizosféricos foram feitas considerando-se o solo aderido às raízes e não liberado por uma leve agitação manual. Assim, o solo foi destorroado até se obterem os 10 gramas necessários para se fazer a diluição inicial.

\section{Planaltina, DF}

Primeiro e segundo ano de cultivo com soja

Os tratamentos utilizados foram: 1- Solo com vegetação nativa (Ecossistema natural); 2- Solo com primeiro ano de cultivo de soja (Agroecossistema 1); e 3- Solo com segundo ano de cultivo de soja (Agroecossistema 2). A disposição dos tratamentos, a semeadura e a infecção da cultivar Doko, assim como o transporte, o armazenamento das amostras e as variáveis utilizadas para avaliar as densidades das populações bacterianas, foram feitos de forma semelhante à do experimento anterior. As amostras de solo foram coletadas aos $0,15,18,23,28,33,44,60,77$, 91 e 120 dias após a semeadura.

\section{Nos primeiros 37 dias após semeadura}

Os efeitos dos fatores ambientais e das práticas agrícolas na comunidade bacteriana foram avaliados durante a fase inicial do ciclo vegetativo da cultivar Doko (primeiros 37 dias após semeadura).

Foram utilizados os tratamentos: 1- Solo com vegetação nativa (Ecossistema natural), e 2- Solo com primeiro cultivo de soja (Agroecossistema); a cultivar Doko foi infectada com a mistura das estirpes BR 33 de Bradyrhizobium elkanni e BR 40 de Bradyrhizobium japonicum. A disposição dos tratamentos e a semeadura foram feitas da mesma forma ao descrito anteriormente.
As amostragens foram feitas aos 0, 9, 12, 14, 16, 19, 21, $23,26,28,30,33,35$ e 37 dias após a semeadura.

Em face do grande número de avaliações feitas nesta etapa, decidiu-se utilizar, para o transporte e o armazenamento das amostras do solo, a metodologia descrita por Wellington \& Williams (1978), cujos efeitos sobre as densidades das populações na comunidade bacteriana durante o período de armazenamento foram testados previamente. Além disso, as populações de actinomicetos foram avaliadas através da enumeração das UFC oriundas de esporos e de hifas, obtidas por processo químico, adaptado de Herron \& Wellington (1990); foram adicionados $7 \mathrm{mg}$ de fenol/mL nos péletes obtidos para a avaliação das populações de actinomicetos oriundas de hifas e de esporos, e as contagens das UFC foram feitas em placas-de-petri, utilizando-se o meio Waksman.

As densidades das populações bacterianas foram determinadas por meio dos números de UFC/g de solo seco das bactérias em geral, das bactérias resistentes a $1,25 \mathrm{e}$ $5,0 \mu \mathrm{g}$ de estreptomicina/mL e a 2,5 e $10,0 \mu \mathrm{g}$ de cloranfenicol $/ \mathrm{mL}$, assim como dos actinomicetos oriundos de hifas e de esporos.

\section{RESULTADOS E DISCUSSÃO}

\section{Sete Lagoas}

No solo com vegetação nativa, a maior densidade foi obtida no início do período experimental (novembro), no tocante às populações de bactérias em geral, com 151,3 x 104 UFC/g de solo seco, e a menor, em maio, no que se refere às populações de bactérias resistentes a $10,0 \mu \mathrm{g}$ de cloranfenicol $/ \mathrm{mL}$, com $0,3 \times 10^{4} \mathrm{UFC} / \mathrm{g}$ de solo seco, enquanto as densidades médias das populações de actinomicetos variaram de 1,7 a 50,1 x $10^{4} \mathrm{UFC} / \mathrm{g}$ de solo seco (Fig. 1). Estas concentrações são semelhantes às encontradas anteriormente por outros autores, em solos de Cerrados, em condições ambientais diferenciadas (Coelho, 1976; Baldani et al., 1982; Raymundo Júnior, 1992).

Neste ecossistema, a representatividade das populações de actinomicetos variou de 5,5 a 76,3\% das populações de bactérias em geral. Estas variações podem ser resultantes do equilíbrio microbiológico, determinado por diversos processos que modificam as condições dos micro-ambientes ocupados pelos microrganismos que, por conseguinte, alteram as densidades das diversas populações na 

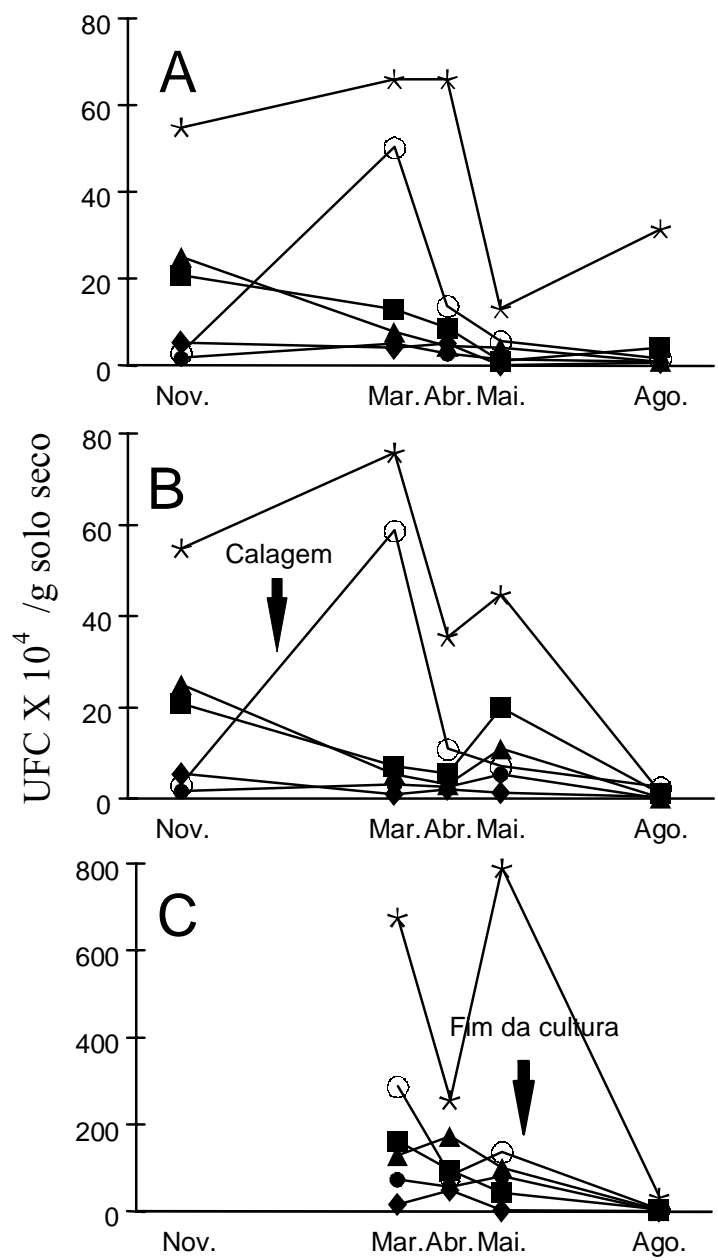

M ê s

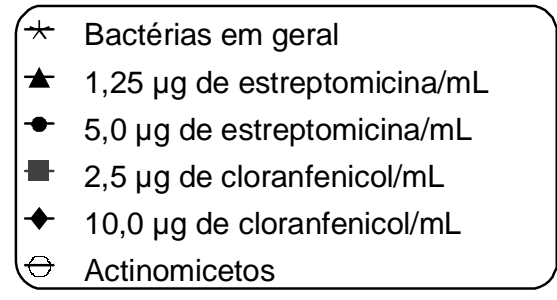

FIG. 1. Dinâmica das populações bacterianas em solo de cerrado, da região de Sete Lagoas, MG, em área com vegetação nativa (A), cultivada com soja (B) e na rizosfera da soja $(C)$. Média de 12 contagens (4 repetições por tratamento e 3 repetições por placa). comunidade (Drozdowicz, 1991; Siqueira et al., 1994).

No solo com vegetação nativa, os baixos valores do coeficiente de correlação das populações de actinomicetos com as demais populações bacterianas demonstram que estas populações não estão correlacionadas (Tabela 1), e evidenciam que as relações entre elas não são diretas.

Observou-se, também, que as freqüências médias das resistências intrínsecas aos antibióticos estreptomicina e cloranfenicol na comunidade bacteriana foram variáveis. Nas populações com resistência a estreptomicina, os valores mínimo de $0,5 \%$ e máximo de $23,6 \%$ foram obtidos, respectivamente, nas concentrações de 5,0 e $1,25 \mu \mathrm{g} / \mathrm{mL}$, enquanto nas resistentes ao cloranfenicol, de modo geral, as freqüências foram mais elevadas, variando de 0,6 a $32,2 \%$, nas concentrações de 10,0 e

TABELA 1. Coeficientes de correlação das populações de actinomicetos com as demais populações bacterianas em solos de Cerrados das regiões de Sete Lagoas, MG (LE) e de Planaltina, DF (LV).

\begin{tabular}{lccc}
\hline Populações $^{1}$ & \multicolumn{3}{c}{ Actinomicetos } \\
\cline { 2 - 4 } & $\begin{array}{c}\text { Solo com } \\
\text { vegetação } \\
\text { nativa }\end{array}$ & $\begin{array}{c}\text { Solo com } \\
\text { soja }\end{array}$ & $\begin{array}{c}\text { Rizosfera } \\
\text { da soja }\end{array}$ \\
\hline & \multicolumn{3}{c}{ Sete Lagoas } \\
B. geral & $0,039^{\mathrm{NS}}$ & $0,803^{* *}$ & $0,938^{* *}$ \\
S1 & $0,314^{\mathrm{NS}}$ & $0,518^{*}$ & $0,899^{* *}$ \\
S2 & $0,172^{\mathrm{NS}}$ & $0,494^{*}$ & $0,781^{* *}$ \\
C1 & $0,221^{\mathrm{NS}}$ & $0,286^{\mathrm{NS}}$ & $0,856^{* *}$ \\
C2 & $0,261^{\mathrm{NS}}$ & $0,224^{\mathrm{NS}}$ & $0,422^{\mathrm{NS}}$ \\
\hline & & Planaltina \\
B. geral & $-0,144^{\mathrm{NS}}$ & $-0,188^{\mathrm{NS}}$ & $0,850^{* *}$ \\
S1 & $-0,231^{\mathrm{NS}}$ & $-0,409^{\mathrm{NS}}$ & $0,920^{* *}$ \\
S2 & $-0,055^{\mathrm{NS}}$ & $-0,186^{\mathrm{NS}}$ & $0,861^{* *}$ \\
C1 & $-0,221^{\mathrm{NS}}$ & $-0,440^{\mathrm{NS}}$ & $0,896^{* *}$ \\
C2 & $-0,100^{\mathrm{NS}}$ & $-0,211^{\mathrm{NS}}$ & $0,868^{* *}$ \\
\hline
\end{tabular}

1 B. Geral: bactérias em geral; S1: bactérias com resistência natural a $1,25 \mu \mathrm{g}$ de estreptomicina/mL; S2: bactérias com resistência natural a $5,0 \mu \mathrm{g}$ de estreptomicina/mL; C1: bactérias com resistência natural a $2,5 \mu \mathrm{g}$ de cloranfenicol $/ \mathrm{mL}$; $\mathrm{C} 2$ : bactérias com resistência natural a $10,0 \mu \mathrm{g}$ de cloranfenicol $/ \mathrm{mL}$.

NS Não-significativo a $5 \%$ de probabilidade.

* Significativo a $5 \%$ de probabilidade.

** Significativo a $1 \%$ de probabilidade 
2,5 $\mu \mathrm{g} / \mathrm{mL}$, respectivamente. Além disso, deve-se destacar que as freqüências de resistência natural apresentadas pelas populações bacterianas a estes antibióticos não apresentaram correlações significativas com as densidades das populações de actinomicetos.

No agroecossistema, verificou-se que o preparo do solo para o cultivo da soja não resultou em alterações bruscas dos números de UFC/g solo seco dessas populações. Modificações no equilíbrio das populações na comunidade bacteriana em solos de Cerrados têm sido atribuídas à calagem (Baldani et al., 1982; Sá et al., 1983). Neste solo, a ausência de resposta das populações bacterianas, e, principalmente, de actinomicetos, à calagem, pode ser explicada pela elevação de apenas 0,6 unidades de $\mathrm{pH}$. Desta forma, o $\mathrm{pH} 4,4$ original deste solo foi elevado para 5,0. Em solo com $\mathrm{pH} 5,0$, a atividade das populações de actinomicetos geralmente é influenciada de forma negativa, considerando-se que estes microrganismos não toleram valores baixos de $\mathrm{pH}$ e que a distribuição e o tamanho das populações está relacionado inversamente com a concentração iônica do hidrogênio (Crawford et al., 1993).

Nestas condições, os coeficientes de correlação significativos das populações de actinomicetos com as populações de bactérias em geral e com as populações bacterianas com resistência natural à estreptomicina demonstram que estas populações foram conjuntamente influenciadas por fatores comuns, ao passo que nas populações de bactérias resistentes ao cloranfenicol, este efeito não é observado (Tabela 1).

As populações de actinomicetos podem interagir com outras populações microbianas por meio da produção de antibióticos (Wellington \& Toth, 1994). Correlações não-significativas nas populações resistentes podem estar relacionadas com a inativação desses antibióticos no solo, principalmente mediante a degradação microbiana (Williams \& Vickers, 1986), dependendo do grau de solubilização na solução do solo e da intensidade com que são adsorvidos às argilas, especialmente do tipo caulinita, componente essencial da fração argila dos solos de Cerrados (Lopes, 1984; Scotti et al., 1988).

$\mathrm{Na}$ rizosfera, verifica-se, por meio dos coeficientes de correlação significativos, que as variações entre as populações de actinomicetos com as populações de bactérias em geral e com as resistentes à estreptomicina e ao cloranfenicol estiveram correlacionadas, com exceção das populações de bactérias resistentes a 10,0 $\mu \mathrm{g}$ de cloranfenicol $/ \mathrm{mL}$, que apresentaram correlação não-significativa. Estes resultados podem ser conseqüência das influências dos fatores determinantes das condições existentes no micro-ambiente onde essas populações estão presentes e que geralmente diferem do solo não-rizosférico (Lynch, 1990).

A Fig. 1 também mostra que na rizosfera, de modo geral, os números de UFC/g de solo seco das populações bacterianas foram superiores aos números do solo não-rizosférico. Esse comportamento está de acordo com observações anteriores, onde se tem evidenciado o estímulo diferenciado da rizosfera nas diversas populações da comunidade microbiana (Campbell \& Greaves, 1990; Brito-Alvarez et al., 1995).

Verifica-se, também, que o estímulo sobre as populações bacterianas não desapareceu completamente após o término do cultivo da soja. O equilíbrio resultante pode ser conseqüência da presença dos resíduos vegetais, principalmente raízes, deixados na área experimental ao final do cultivo. Tem-se observado que a deposição do resíduo orgânico em solos com culturas anuais estimula a comunidade microbiana, o qual ocorre de forma intensa logo após a colheita, sendo que o estímulo depende da quantidade e qualidade dos resíduos adicionados (Whipps, 1990).

\section{Planaltina}

Com primeiro e segundo ano de cultivo com soja

Os dados referentes às densidades das populações bacterianas em solo de Cerrado com vegetação nativa mostram variações acentuadas durante o período de 120 dias em que se conduziu o experimento (Fig. 2). A menor densidade foi obtida na semeadura da soja nas populações de bactérias resistentes a $10,0 \mu \mathrm{g}$ de cloranfenicol/mL, com $0,01 \times 10^{4} \mathrm{UFC} / \mathrm{g}$ solo seco, e a maior, 120 dias após, nas populações de bactérias em geral, com $4 \times 10^{4}$ $\mathrm{UFC} / \mathrm{g}$. 

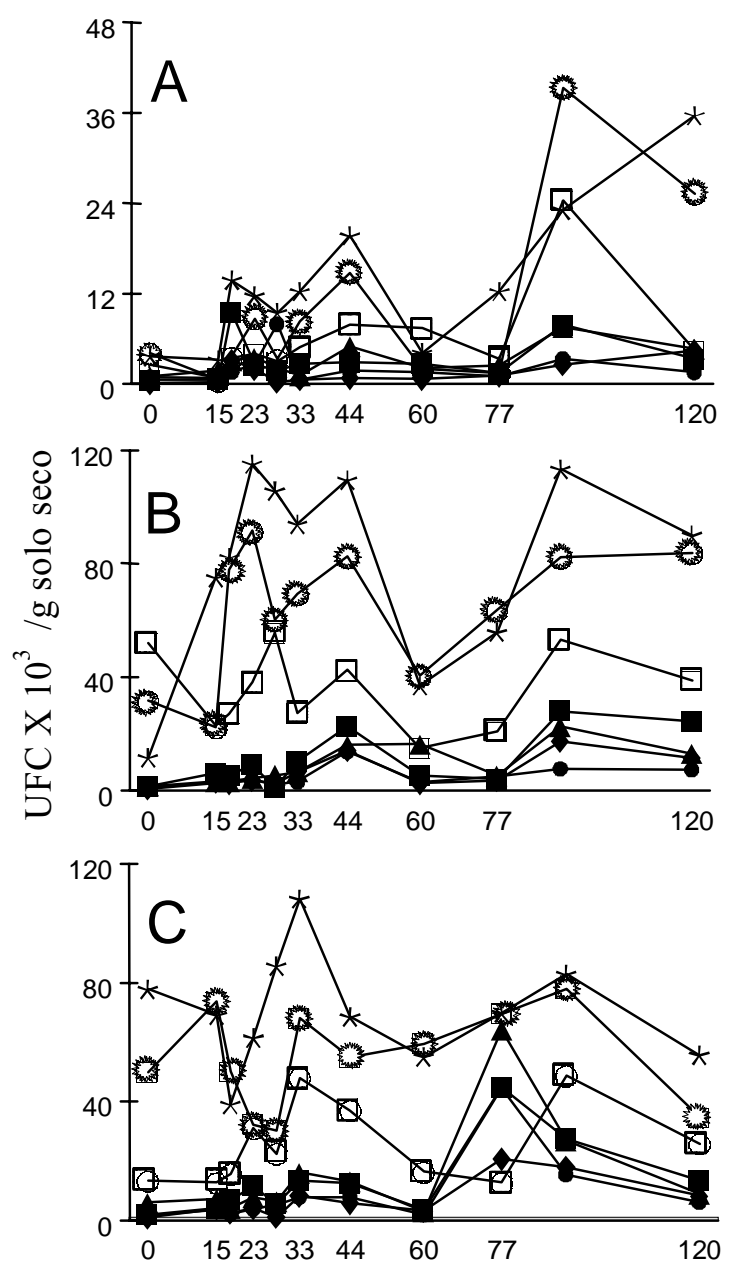

Dias após semeadura

$\begin{array}{ll}* & \text { Bactérias em geral } \\ \star & 1,25 \mu \mathrm{g} \text { de estreptomicina } / \mathrm{mL} \\ - & 5,0 \mu \mathrm{g} \text { de estreptomicina } / \mathrm{mL} \\ & 2,5 \mu \mathrm{g} \text { de cloranfenicol } / \mathrm{mL} \\ & 10,0 \mu \mathrm{g} \text { de cloranfenicol } / \mathrm{mL} \\ \text { 日 } & \text { Actinomicetos hifas } \\ & \text { Actinomicetos esporos }\end{array}$

FIG. 2. Dinâmica das populações bacterianas em solo de cerrado, da região de Planaltina, DF, em área com vegetação nativa $(A), e m$ área com $1^{\circ}(B)$ e $2^{\circ}(C)$ ano de cultivo com soja. Média de 12 contagens (4 repetições por tratamento e 3 repetições por placa).
Estas variações podem ser decorrentes das condições climáticas, representadas principalmente pela distribuição não-uniforme das precipitações pluviais ocorridas durante o período da condução experimental. Este efeito é mais acentuado, em virtude da baixa capacidade de armazenamento de água disponível que os solos de Cerrado normalmente apresentam (Lopes, 1984).

Aos 91 e 120 dias após a semeadura, as variações nos números de UFC/g de solo seco das populações bacterianas foram menos acentuadas, o que evidencia um novo equilíbrio dessas populações. Apesar de estas coletas serem feitas durante a estação seca da região (6 de abril e 5 de maio), observou-se que nos sete dias anteriores as precipitações pluviais totalizaram 20,4 e 18,2 mm, respectivamente.

Quanto aos actinomicetos, as densidades mínima e máxima das populações originárias de esporos foram, respectivamente, de 0,05 e $7,9 \times 10^{4} \mathrm{UFC} / \mathrm{g}$ de solo seco, e no tocante às provenientes de hifas, foram de 0,08 e 5 x $10^{4} \mathrm{UFC} / \mathrm{g}$ de solo seco. Com isso, as relações esporos/hifas, mínima de 0,7 , e a máxima de 4,0, foram obtidas, respectivamente, aos 15 e 60 dias após a semeadura. Estas diferenças podem ser atribuídas, em parte, aos fatores determinantes da dormência e germinação dos esporos no solo. A influência de vários fatores tem sido estudada em condições de laboratório, principalmente a temperatura e o teor de umidade (Kalakoustskii \& Agre, 1973). Entretanto, em condições de campo, as amplitudes dos efeitos dos agentes determinantes da dormência e germinação dos esporos ainda não estão completamente definidas.

No ecossistema natural e no agroecossistema, as relações das populações de actinomicetos com as populações de bactérias em geral e com as populações resistentes, a estreptomicina e cloranfenicol foram indiretas (Tabela 1); e na rizosfera da soja, os coeficientes de correlação significativos das populações de actinomicetos com as populações de bactérias em geral $(\mathrm{r}=0,850 * *)$ com as populações de resistentes a $1,25(\mathrm{r}=0,920 * *)$ e $5,0(\mathrm{r}=0,861 * *) \mu \mathrm{g}$ de estreptomicina/mL e a $2,5\left(\mathrm{r}=0,896^{* *}\right)$ e $10\left(\mathrm{r}=0,868^{* *}\right) \mu \mathrm{g}$ de cloranfenicol $/ \mathrm{mL}$ demonstram que estas populações estiveram relacionadas com efeitos resultantes de fatores comuns. 
No solo de Cerrado com primeiro e segundo ano de cultivo com soja, as populações na comunidade bacteriana foram influenciadas com estímulos variáveis (Fig. 2). No primeiro ano de cultivo, as densidades das populações bacterianas variaram de $0,06 \times 10^{4}$ a $31,6 \times 10^{4} \mathrm{UFC} / \mathrm{g}$ de solo seco, enquanto, no segundo ano as variações ocorreram entre $0,1 \times 10^{4}$ e $10,9 \times 10^{4} \mathrm{UFC} / \mathrm{g}$ de solo seco.

A superioridade numérica das populações bacterianas nestes agroecossistemas, em relação ao ecossistema natural, confirma resultados obtidos em regiões subtropicais do Rio Grande do Sul, em cujos campos nativos as populações bacterianas foram numericamente inferiores às dos sistemas cultivados (Nuernberg et al., 1984; Cattelan \& Vidor, 1990).

As freqüências médias das resistências intrínsecas das populações bacterianas aos antibióticos também apresentaram variações. No solo, no primeiro ano de cultivo, as resistências à estreptomicina e ao cloranfenicol variaram, respectivamente, de $2,1 \%$ a $44,4 \%$ e de $2,2 \%$ a $27,0 \%$, enquanto no solo de segundo ano as representatividades das populações resistentes a estes antibióticos variaram de 1,9\% a $92,0 \%$ e de $1,3 \%$ a $64,1 \%$, respectivamente. Isto sugere que o desequilíbrio bacteriano foi mais acentuado no solo no segundo ano de cultivo de soja.

Apesar de as amplitudes das freqüências médias das resistências intrínsecas a esses antibióticos terem sido maiores no solo com segundo ano de cultivo, não foi observada a predominância de valores mais elevados em nenhum desses agroecossistemas. Por outro lado, a utilização agrícola deste solo, de modo geral, não resultou em desequilíbrios acentuados das populações de actinomicetos provenientes de hifas e de esporos. No solo com primeiro cultivo, observa-se que as densidades mínima e máxima nas populações oriundas de hifas foram respectivamente de $1,5 \times 10^{4}$ e $5,5 \times 10^{4} \mathrm{UFC} / \mathrm{g}$ de solo seco, e nas provenientes de esporos, de $4,2 \times 10^{4} \mathrm{e}$ $9,1 \times 10^{4} \mathrm{UFC} / \mathrm{g}$ de solo seco. No solo com segundo ano de cultivo, as densidades mínima e máxima nas populações de hifas e esporos foram, respectivamente, de $1,3 \times 10^{4}$ e $4,8 \times 10^{4} \mathrm{UFC} / \mathrm{g}$ de solo seco e $3 \times 10^{4}$ e $7,8 \times 10^{4} \mathrm{UFC} / \mathrm{g}$ de solo seco.

Observou-se, também, que no primeiro ano de cultivo as relações esporos/hifas variaram de 1,1 a 3,1 , enquanto no solo com segundo ano de cultivo, as variações ocorreram entre 1,0 e 5,8. Entretanto, não houve predominância de valores mais elevados em nenhum destes solos. Isto sugere que em circunstâncias específicas, as condições ambientais desfavoráveis para o desenvolvimento das populações de actinomicetos podem resultar em maiores produções de esporos.

Nos primeiros 37 dias após a semeadura

Em solo de Cerrado com vegetação nativa, as densidades das populações bacterianas mostram variações durante o período de 37 dias em que se conduziu o experimento (Fig. 3). As densidades das populações de bactérias em geral apresentaram variações mais acentuadas, enquanto as populações bacterianas com resistência natural à estreptomicina e ao cloranfenicol mantiveram-se relativamente estáveis neste período.

Em relação às populações de actinomicetos, de modo geral, verifica-se que as densidades da fração esporos foram ligeiramente superiores às da fração hifas. As densidades mínima e máxima nas populações oriundas de esporos foram, respectivamente, de $0,06 \times 10^{4}$ e $3,2 \times 10^{4} \mathrm{UFC} / \mathrm{g}$ de solo seco, e nas provenientes de hifas, de $0,06 \times 10^{4}$ e $1,6 \times 10^{4} \mathrm{UFC} / \mathrm{g}$ de solo seco, ao passo que as relações esporos/hifas mínima de 0,4 e a máxima de 2,6 foram obtidas, respectivamente, aos 9 e 37 dias após a semeadura.

Este comportamento está de acordo com as observações anteriores, de que as populações de actinomicetos ocorrem no solo principalmente na forma de esporos, exceto por pequenos períodos, quando os nutrientes estão disponíveis e há predominância da fração hifa, colonizando resíduos animais e vegetais (Herron \& Wellington, 1990; Wellington et al., 1990).

Nas populações de actinomicetos, as variações no número de $\mathrm{UFC} / \mathrm{g}$ de solo seco provenientes da fração esporos, estiveram correlacionadas com o número de UFC originários da fração hifas $\left(\mathrm{r}=0,739^{* *}\right)$. Este efeito também foi observado nas populações de bactérias em geral, em relação às populações oriundas de esporos $(\mathrm{r}=0,459 * *)$ e de hifas $(\mathrm{r}=0,408 * *)$.

O manejo do solo para cultivo geralmente provoca desequilíbrios pronunciados nas populações da 


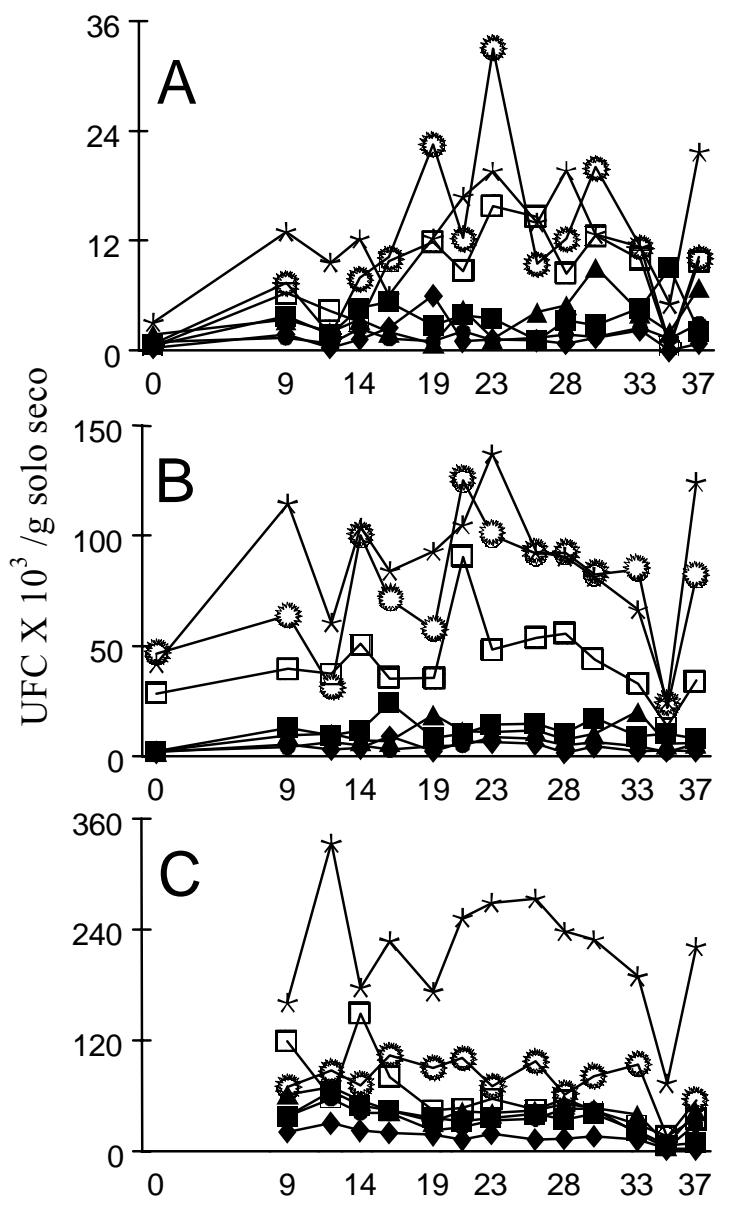

Dias após semeadura

$\begin{array}{ll}* & \text { Bactérias em geral } \\ & 1,25 \mu \mathrm{g} \text { de estreptomicina/mL } \\ & 5,0 \mu \mathrm{g} \text { de estreptomicina } / \mathrm{mL} \\ & 2,5 \mu \mathrm{g} \text { de cloranfenicol } / \mathrm{mL} \\ \boxminus & 10,0 \mu \mathrm{g} \text { de cloranfenicol/mL } \\ \boxminus & \text { Actinomicetos hifas } \\ & \text { Actinomicetos esporos }\end{array}$

FIG. 3. Dinâmica das populações bacterianas em solo de cerrado, da região de Planaltina, DF, em área com vegetação nativa $(A)$, no $1^{\circ}$ cultivo com soja (B) e na rizosfera da soja (C). Média de 12 contagens (4 repetições por tratamento e 3 repetições por placa). comunidade microbiana (Cattelan \& Vidor, 1990); a aração, a adição de adubos minerais e a modificação do $\mathrm{pH}$ do solo por meio da calagem têm sido considerados como os principais fatores que resultam nestes desequilíbrios (Siqueira et al., 1994).

As populações de actinomicetos também foram estimuladas pelo preparo do solo para cultivo da soja. Os números médios de UFC/g de solo seco das populações originárias de esporos foram ligeiramente superiores aos números das populações provenientes de hifas; as relações esporos/hifas geralmente foram mais elevadas do que no solo com vegetação nativa, variando de 1,4 a 2,5.

As relações esporos/hifas mais elevadas demonstram que as práticas agrícolas utilizadas resultaram em estímulos diferenciados no tocante às frações hifas e esporos das populações de actinomicetos. Isto evidencia que o preparo do solo para o cultivo, além de estimular, também é mais estressante para o desenvolvimento das populações desses microrganismos. A produção mais elevada de esporos seria uma conseqüência desse fato, considerando-se que os esporos são estruturas de resistência que permitem a estas populações sobreviverem em condições ambientais desfavoráveis (Kalakoutskii \& Pouzharitskaja, 1973). Nos solos, tem-se observado que vários fatores físicos e químicos apresentam como características o efeito diferenciado sobre os esporos e as células vegetativas de actinomicetos (Herron \& Wellington, 1990). Entretanto, tem-se observado que as condições de $\mathrm{pH}$ do solo e as exigências térmicas para germinação dos esporos são normalmente próximas das que favorecem o crescimento da hifa (Kalakoutskii \& Pouzharitskaja, 1973).

$\mathrm{Na}$ rizosfera, não houve grandes variações na comunidade bacteriana. De modo geral, as populações foram estimuladas, exceções feitas às populações de actinomicetos oriundas de hifas e esporos, cujos números de UFC/g de solo seco permaneceram semelhantes ao solo não-rizosférico. O efeito rizosférico não é específico, mas as raízes geralmente favorecem as populações de bactérias Gram-negativas, que apresentam elevada taxa de crescimento, respondem à adição de aminoácidos e açúcares solúveis, e produzem ácidos pela adição da glicose, proporcionando nichos atrativos para a maioria dos microrganismos quimiorganotróficos oportunistas que podem explorá-los (Bazin et al., 1990). 
Desta forma, a ausência de estímulo observada nas populações de actinomicetos presentes na rizosfera da soja pode estar relacionada com o desenvolvimento desses microrganismos, que ocorre de forma mais lenta do que as demais bactérias e por conseguinte não conseguem se estabelecer em substratos orgânicos nos quais outros microrganismos se instalam mais rapidamente (Siqueira et al., 1994). Além disso, deve-se considerar que os efeitos rizosféricos podem ser estimulantes ou inibitórios nas diferentes populações microbianas da comunidade rizosférica (Drozdowicz, 1991).

\section{CONCLUSÕES}

1. O preparo do solo e o cultivo da soja nas regiões de Sete Lagoas, MG, e Planaltina, DF, resulta em modificações das densidades populacionais de bactérias em geral, das resistentes à estreptomicina, e ao cloranfenicol e de actinomicetos.

2. As populações de actinomicetos são estimuladas, principalmente as provenientes da fração esporos, aumentando a representatividade destas populações na comunidade bacteriana; as freqüências médias das populações bacterianas resistentes à estreptomicina e ao cloranfenicol apresentam variações, sem correlações significativas com as populações de actinomicetos.

3. Na rizosfera da soja, as densidades das populações bacterianas são superiores ao solo nãorizosférico, exceto nas populações de actinomicetos cujas densidades permanecem semelhantes; nestas condições, as populações de bactérias em geral e as das resistentes à estreptomicina e ao cloranfenicol apresentam correlações significativas com as populações de actinomicetos.

\section{AGRADECIMENTOS}

Aos Drs. Allert Rosa Suhet e Antônio Álvaro Corsetii Purcino e demais funcionários da EmbrapaCentro Nacional de Pesquisa de Agrobiologia, Embrapa-Centro de Pesquisa Agropecuária dos Cerrados e Embrapa-Centro Nacional de Pesquisa de Milho e Sorgo, pelo apoio técnico fornecido.

\section{REFERÊNCIAS}

BALDANI, J.I.; BALDANI, V.L.D.; XAVIER, D.F.; BODDEY, R.M.; DÖBEREINER, J. Efeito da calagem no número de actinomicetos e na porcentagem de bactérias resistentes à estreptomicina na rizosfera de milho, trigo e feijão. Revista de Microbiologia, São Paulo, v.13, n.3, p.250-263, 1982.

BARRETO, W. de O.; DURIEZ, M.A. de M.; JOHAS, R.A.L. Análises químicas. In: EMBRAPA. Serviço Nacional de Levantamento e Conservação de Solos. (Rio de Janeiro, RJ). Manual de métodos de análise do solo. Rio de Janeiro, 1979. Parte 2, paginação irregular.

BAZIN, M.J.; MARKHAM, P.; SCOTTI, E.M.; LYNCH, J.M. Population dynamics and rhizosphere interactions. In: LYNCH, J.M. (Ed.). The Rhizosphere. Chichester: John Wiley, 1990. p.99-126. (Wiley series in ecological and applied microbiology).

BRITO-ALVAREZ, M.A.; DE GAGNE, S.; ANTOUN, $\mathrm{H}$. Effect of compost on rhizosphere microflora of the tomato and the incidence of plant growth-promoting rhizobacteria. Applied and Environmental Microbiology, Washington, v.61, p.194-199, 1995.

CAMPBELL, R.; GREAVES, M.P. Anatomy and community strutcture of the rizosphere. In: $\mathrm{LYNCH}$, J.M. (Ed.). The Rhizosphere. Chichester: John Wiley, 1990. p.11-34. (Wiley series in ecological and applied microbiology).

CATTELAN, A.J.; VIDOR, C. Sistemas de culturas e a população microbiana do solo. Revista Brasileira de Ciência do Solo, Campinas, v.14, p.125-132, 1990.

COELHO, R.R.R. Ocorrência de actinomicetos em solos de cerrado, capazes de utilizar compostos aromáticos. Rio de Janeiro: UFRJ, 1976. 111p. Tese de Mestrado.

CRAWFORD, D.L.; LYNCH, J.M.; OUSLEY, M.A. Isolation and characterization of actinomycete antagonists of a fungal root pathogen. Applied and Environmental Microbiology, Washington, v.59, p.3899-3905, 1993.

DROZDOWICZ, A.G. Microbiologia ambiental. In: ROITMAN, I.; TRAVASSOS, L.R.; AZEVEDO,

Pesq. agropec. bras., Brasília, v.34, n.5, p.801-811, maio 1999 
J.L. (Eds.). Tratado de microbiologia. Rio de Janeiro: Manole, 1991. v.2, p.1-102.

HERRON, P.R.; WELLINGTON, E.M.H. New method for extraction of streptomycete spores from soil and application to the study of lysogeny in sterile amended and nonsterile soil. Applied and Environmental Microbiology, Washington, v.56, n.5, p.1406-1412, 1990.

KALAKOUTSKII, L.V.; AGRE, N.S. Endospore of actinomycetes: dormancy and germination. In: SYKES, G.; SKINNER, F.A. (Eds.). Actinomycetales: characteristics and practical importance. London: Academic Press, 1973. p.179-193.

KALAKOUTSKII, L.V.; POUZHARITSKAJA, L.M. The streptomyces spore: its distinct features and germinal behaviour. In: SYKES, G.; SKINNER, F.A. (Eds.). Actinomycetales: characteristics and practical importance. London: Academic Press, 1973. p. $155-171$

KAMEL, Z.; KHALIL, M.S.; SHALABY, A.M. Calcium and the biological activities of two Streptomyces species isolated, from the rhizosphere of soybean plants. Journal of Basic Microbiology, Berlin, v.29, p.31-39, 1989

LOPES, A.S. Solos sob cerrado: características, propriedades e manejo. Piracicaba: Associação Brasileira para Pesquisa da Potassa e do Fosfato, 1984. 162p.

LYNCH, J.M. Introduction: some consequences of microbial rhizosphere competence for plant and soil. In: LYNCH, J.M. (Ed.). The Rhizosphere. Chichester: John Wiley, 1990. p.1-10. (Wiley series in ecological and applied microbiology).

NUERNBERG, N.J.; VIDOR, C.; STAMMEL, J.C. Efeito de sucessões de culturas e tipos de adubação na densidade populacional e atividade microbiana do solo. Revista Brasileira de Ciência do Solo, Campinas, v.8, p.197-203, 1984

PANTHIER, J.J.; DIEM, H.G.; DOMMERGUES, Y. Rapid method to enumerate and isolate soil actinomycetes antagonistic towards rhizobia. Soil Biology and Biochemistry, Oxford, v.11, p.443-445, 1979.

PEREIRA, J.C. Ecologia da comunidade bacteriana em solos de cerrados. Itaguaí: URRRJ, 1995. 172p. Tese de Doutorado.
PEREIRA, J.C.; NEVES, M.C.P.; DROZDOWICZ, A. Quantificações das populações de bactérias em geral, de bactérias resistentes a antibióticos e de actinomicetos em solos. Seropédica: EmbrapaCNPAB, 1996. 20p. (Embrapa-CNPAB. Documentos, 26).

PERES, J.R.R.; SUHET, A.R.; VARGAS, M.A.T. Fixação do $\mathrm{N}_{2}$ em leguminosas cultivadas em solos de cerrados. In: CARDOSO, E.J.B.N.; TSAI, S.M.; NEVES, M.C.P. (Eds.). Microbiologia do solo Campinas: Sociedade Brasileira de Ciência do Solo, 1992. p.213-218.

RAVERKAR, K.P.; KONDE, B.K. Effect of Rhizobium and Azospirillum lipoferum inoculation on the nodulation, yield and nitrogen uptake of peanut cultivars. Plant and Soil, Dordrecht, v.106, p.294-252, 1988.

RAYMUNDO JÚNIOR, O.R. Fungos filamentosos, actinomicetos e ácidos húmicos, em diferentes profundidades de Latossolo Vermelho Amarelo textura média em área de cerrado, no município de Corumbataí, SP. Rio Claro: UNESP, 1992. 149p. Tese de Mestrado.

SÁ, N.M.H.; SCOTTI, M.R.M.M.L.; VARGAS, M.A.T.; DÖBEREINER, J. Resistência natural à estreptomicina, e eficiência de estirpes de Rhizobium nativas nos cerrados, associadas a Stylosanthes. Pesquisa Agropecuária Brasileira, Brasília, v.18, n.3, p.213-218, 1983.

SCOTTI, M.R.M.M.L.; SÁ, N.M.H.; VARGAS, M.A.T.; DÖBEREINER, J. Avaliação da resistência à tetraciclina, kanamicina, cloranfenicol de estirpes de Bradyrhizobium japonicum e Bradyrhizobium de Stylosanthes isoladas de solo de cerrados. Revista de Microbiologia, São Paulo, v.19, p.60-66, 1988.

SIQUEIRA, J.O.; MOREIRA, F.M.S.; GRISI, B.M.; HUNGRIA, M.; ARAÚJO, R.S. Microrganismos e processos biológicos do solo: perspectiva ambiental. Brasília: Embrapa-SPI, 1994. p.142. (Embrapa-CNPAF. Documentos, 45).

THORNTON, H.G. On the development of a standardized agar medium for counting soil bacteria with special regard to the repression of spreading colonies. Annals of Applied Biology, Cambridge, v.9, p.241-274, 1922.

TSAI, S.M.; BARAIBAR, A.V.L.; ROMANI, V.L.M. Efeito de fatores do solo. In: CARDOSO, E.J.B.N.; TSAI, S.M.; NEVES, M.C.P. (Eds.). Microbiologia 
do solo. Campinas: Sociedade Brasileira de Ciência do Solo, 1992. p.59-72.

WAKSMAN, S.A. The actinomycetes, classification, identification and descriptions of genera and species. Baltimore: The Williams \& Wilkins, 1961. 260p.

WARDLE, D.A.; PARKINSON, D. Interactions between microclimatic variables and the soil microbial biomass. Biology and Fertility of Soils, Berlin, v.9, n.3, p.273-280, 1990.

WELLINGTON, E.M.H.; CRESSWELL, N.; SAUNDERS, V.A. Growth and survival of streptomycete inoculants and extent of plasmid transfer in sterile and nonsterile soil. Applied and Environmental Microbiology, Washington, v.56, n.5, p.1413-1419, 1990.
WELLINGTON, E.M.H.; TOTH, I.K. Actinomycetes. In: WEAVER, R.W.; ANGLE, J.S.; BOTTOMLEY, P.S. (Eds.). Methods of soil analysis. 3.ed. Madison: Soil Science Society of America, 1994. p.269-290.

WELLINGTON, E.M.H.; WILLIAMS, S.T. Preservation of actinomycete inoculum in frozen glycerol. Microbios Letters, Cambridge, v.6, p.151-157, 1978.

WHIPPS, J.M. Carbon economy. In: LYNCH, J.M. (Ed.). The Rhizosphere. Chichester: John Wiley, 1990. p.59-98. (Wiley series in ecological and applied microbiology)

WILLIAMS, S.T.; VICKERS, J.C. The ecology of antibiotic production. Microbiology Ecology, New York, v.12, p.43-52, 1986. 